Article

\title{
Assessing the Potential of Climate Change Mitigation Actions in Three Different City Types in Finland
}

\author{
Riikka Kyrö *, Jukka Heinonen, Antti Säynäjoki and Seppo Junnila
}

Aalto University School of Engineering, P.O. Box 11200, Aalto 00076, Finland;

E-Mails: jukka.heinonen@aalto.fi (J.H.); antti.saynajoki@aalto.fi (A.S.); seppo.junnila@aalto.fi (S.J.)

* Author to whom correspondence should be addressed; E-Mail: riikka.kyro@aalto.fi;

Tel.: +358-50-364-3828.

Received: 18 May 2012; in revised form: 27 June 2012 / Accepted: 4 July 2012 /

Published: 10 July 2012

\begin{abstract}
As the effects of global warming have become more evident, ambitious short-term greenhouse gas emission reduction targets have been set in recent years. Many cities worldwide have adopted an active approach to climate change mitigation, but policy makers are not always knowledgeable of the true effects of their planned mitigation action. The purpose of this paper is to evaluate the effectiveness of different mitigation strategies in achieving low-carbon urban communities. The assessment is conducted via means of consumption based hybrid life-cycle assessment, which allows the reduction potential to be analyzed from the perspective of an individual resident of the urban community. The assessed actions represent strategies that are both adopted by the case cities and possible to implement with current best practices in Finland. The four assessed actions comprise: (1) dense urban structure with less private driving; (2) the use of energy production based on renewable sources; (3) new low-energy residential construction; and (4) improving the energy efficiency of existing buildings. The findings show that the effectiveness depends greatly on the type of city, although in absolute terms the most significant reduction potential lies with lowering the fossil fuel dependence of the local energy production.
\end{abstract}

Keywords: climate change; carbon footprint; greenhouse gases; urban communities; life-cycle assessment; consumption; energy 


\section{Introduction}

At present, already half of the world's population resides in urban communities, which are consequently accountable for a vast majority of global greenhouse gas (GHG) emissions [1]. Recent research has also indicated that even the per capita emissions may be higher in cities compared to the sub-urban or rural areas due to higher income levels and consequent consumption volume [2-7]. The role of urban carbon management is therefore essential in attempting to mitigate climate change. Many cities worldwide have taken on the challenge and adopted an active approach to climate change mitigation; however, urban policy makers are not always knowledgeable of the true effects of their planned mitigation action. The problematic possibly stems from difficulties in defining and managing GHG emissions accountable to a city. Most city level GHG assessments have focused only on the direct emissions occurring within the city borders, and have failed to account for the so-called carbon leakage. Carbon leakage traditionally refers to the relocation of carbon intensive industries outside geographical borders, which may be calculated as an emission reduction to a certain country, even though global emissions might actually increase [8,9]. Similar carbon leakage also exists between cities within one country, but this phenomenon has received less attention in the literature.

Consumption based GHG assessments provide one solution for the above-described assessment problem [6,10]. The consumption approach assumes cities to be demand and consumption centers, where residents exploit goods predominantly produced outside the city borders [6,11]. An extreme example has been presented by Schulz (2007) [12] who demonstrates that $90 \%$ of all the goods consumed in Singapore are actually imported from outside the city-state. The consumption approach stresses the importance of not limiting the scopes of GHG assessments geographically. Accounting for all GHG emissions associated with the consumption of goods and services provides a basis for equal comparisons between different types of cities with their particular characteristics. The consumptionbased approach also allows for focusing on the right action by assessing the true global mitigation potential of different strategies.

This study was set to determine the GHG mitigation potential of a few commonly accepted actions to reach short-term climate policy goals. More specifically, the effects of the actions were compared between different city types. The study employs a consumption based, hybrid life-cycle assessment model paired with in-depth, qualitative analysis of the results. Using a multiple case study approach, three different types of cities and four different types of mitigation strategies are assessed. The assessments are conducted for the cities of Helsinki, Tampere and Porvoo, all representing different types of city structures yet with somewhat similar demographics. The strategies are all stated as the preferred mitigation action by at least one of the three cities and considered current best practice in Finland. The four assessed actions comprise denser urban structure; cleaner energy production; new low-energy residential development; and improving the energy efficiency of existing buildings. The study demonstrates how different strategies are effective in different types of cities, suggesting that a single action is insufficient for general city level carbon management. Nevertheless, in absolute terms the effect of cleaner energy production was found to be the greatest.

The remainder of the paper is structured so that the next section describes the method, assessment model, and data used in the study. Section 3 presents the base assessment and outlines the assessed best practice mitigation action. The climate mitigation impacts are then presented in detail in the 
following Section 4. After the results, some deficiencies of the study are addressed. Finally, a few key conclusions and suggestions for future research conclude the paper.

\section{Method}

Within the field of life-cycle assessment (LCA), process-LCA is the traditional and the most utilized method. Process-LCAs attribute the emission to a certain good by process based, energy and mass flow assessments. The method is potentially highly accurate, but suffers from a few inherent limitations. First, the amount of processes adding to the emissions inventory of a certain good is often very large in cradle-to-grave assessments, which makes the assessments very laborious and time consuming. Second, the assessments suffer from a truncation error, resulting from an inevitable system boundary selection [13]. The errors may become significant even with the inclusion of multiple production chain processes [14]. Finally, the energy and mass flow data needed for the assessments are often not readily available $[13,15]$.

An alternative to the traditional process-LCA is an input-output-LCA (IO-LCA). An IO-LCA assesses the environmental impacts attributable to a certain good (the outputs), based on monetary flows (the inputs). The method is based on output tables that describe known industry interdependencies within an economy according to national accounts. Based on these, the tables sum together all emissions within an economy related to a monetary transaction on a certain sector. The method is similar to the input-output statistics of national accounts, but in this case the output tables include environmental data in addition to economic activity relations. Typical environmental impact categories included in IO-LCAs comprise toxic materials and atmospheric emissions, such as GHGs. The output tables divide the economy into industry-based sectors to fully acknowledge the entire economy. This division is one of the primary sources of uncertainty in input-output-analysis $[13,16]$. The output tables are averages that may include figures from very different industries, and may not describe the object of the inquiry well. In addition, possible temporal (inflation and currency rate) and regional (industry structure) asymmetries in both the data and the model, along with the assumption of domestic production of imports create possible sources of bias. However, contrary to process-LCAs, the method is non-laborious and non-time consuming to use [17]. The emissions inventory is also always complete with regard to the included number of transactions between sectors in the production and delivery chain, so that the assessment boundary cutoff excludes only non-monetary transactions [18]. In addition, monetary input data is often easier to obtain than data for process analyses. IO-LCAs have been found to be particularly feasible in assessing the environmental effect of services [19].

The third category, hybrid-LCAs, has emerged to combine the strengths of the two presented approaches and to reduce the inherent weaknesses related to them $[13,15,16,20]$. As described above, the IO and process method have different uncertainties, creating space for a hybrid approach. The first hybrid approaches date back to the 1970s, but the method has become more popular in environmental impact assessments after the late 1990s. In hybrid-LCAs, full coverage of production and delivery chains is possible to maintain with the use of input-output tables, but the accuracy is raised with the utilization of process data for the assessment of the most important processes.

Hybrid-LCAs can be further divided into three categories [13,20]. An integrated hybrid-LCA incorporates detailed unit process level information in physical quantities into the input-output model, 
representing the surrounding economy that embeds the process-based system. The second option, input-output-based hybrid analysis can be utilized when detailed monetary data within the IO sectors are available. Input-output-based hybrid analyses disaggregate the most significant IO sectors further to incorporate specific process data. Finally, a tiered hybrid-LCA assesses the most important first order and lower stream processes with process data, whereas the rest of the production and supply chain emissions are assessed with the IO approach.

This study employs an application of the tiered hybrid-LCA, which calculates global GHG emissions from private consumption based on IO-LCA, but with the most significant GHG sources replaced with process data. The model employed was developed earlier by the authors, and a more detailed description may be found in previous publications [3,5]. The model predominantly utilizes the output matrices of the EIO-LCA developed by Carnegie-Mellon University [21], with purchasing power parity corrections to fit the model with Finnish input data. The EIO-LCA was selected primarily due to it being the most disaggregated model available. Additionally, the Finnish economy is a small and very open economy with over $50 \%$ of the consumption goods being imported, which further justifies the selection of a foreign model. Moreover, during the course of the development of the applied model, a comparison of the results with output vectors taken from the Finnish ENVIMAT model [22] was made along with many other reliability checks, as described in detail in [3,5]. The results of the comparisons were very similar.

For the purpose of this study, the input data comprise the private consumption volumes obtained from a Finnish consumer survey [23]. These describe the consumption of an average consumer in each city in a very detailed form. For the purpose of the study and in order to fit the data with the industry sectors of the assessment model, the data were first merged into 59 consumption sectors. After the assessment of the GHGs caused by each sector, the sectors were merged further to five broader consumption categories to allow for a coherent presentation of the results. To better capture the emissions derived from public transport, the Finnish ENVIMAT model [22] was employed for this sector, as it is very different in Finland compared to the U.S. Furthermore, city specific emission factors were utilized to calculate emissions from local energy production [24] and private driving fuel combustion [25], the two largest sources of emissions according to earlier studies.

Finally, data on current requirements and existing goals for building energy efficiency [26,27], a national travel survey on the effects of density on the private driving related emissions [28], along with a previous case study on the GHG emissions derived from new residential development [29] were all used in the assessments of the different mitigation strategies.

\section{Case Cities}

Three case cities from Finland are addressed in the study: the capital city of Helsinki, a smaller, adjacent city, Porvoo, and a larger inland city, Tampere. The city of Porvoo, located approximately $50 \mathrm{~km}$ east of Helsinki, is strongly influenced by the capital with regard to e.g., daily commuting, and recreational activities whereas Tampere, the third largest city in the country, is more independent.

The city structures of the three case cities differ significantly. Helsinki is the densest city in Finland with over 3000 residents per square $\mathrm{km}$. Tampere is less dense but housing is still dominated by multi-story apartment buildings, whereas Porvoo is more of a rural city with very low density and 
detached houses as the dominant form of housing. Besides population density, the public transport options provided are very different for the cities. Helsinki provides the most diverse public transportation infrastructure with metro, tram, and commuter train and bus connections. In Tampere local and long distance buses as well as long distance trains are available, while in Porvoo only rare local buses and long distance buses serve the residents. These characteristics are also reflected in the vehicle kilometers traveled (VKmT) by the average resident as Table 1 shows.

Table 1. Characteristics of the three case cities.

\begin{tabular}{lccc}
\hline & Helsinki & Porvoo & Tampere \\
\hline $\begin{array}{l}\text { Number of inhabitants } \\
\text { Population density (residents/sqm) }\end{array}$ & 565,000 & 48,000 & 206,000 \\
$\begin{array}{l}\text { Apartment buildings/detached or } \\
\text { terraced housing (\% of sqm) }\end{array}$ & 3010 & 73 & 365 \\
Living space per capita (sqm) & $80 / 20$ & $29 / 71$ & $63 / 37$ \\
Public transport options & 34 & 39 & 36 \\
Private driving (VKmT/a/capita) & Trams, trains, buses & Buses & Buses \\
Annual net income (€/capita) & 8100 & 18,400 & 12,600 \\
Annual private consumption (€/capita) & 21,700 & 22,000 & 15,900 \\
\hline
\end{tabular}

Another key difference between the cities is found with fuel combustion related emission factors in the local power plants, especially between Porvoo and the other two cities. All three cities employ combined heat and power (CHP), which is a very effective means of energy production as such. However, Porvoo produces over $70 \%$ of its energy from renewable sources such as forest residues, whereas in Helsinki and Tampere the CHP production is predominantly fossil fuel based [23].

Finally, the average residents in Helsinki and Porvoo share the same affluence level with annual net earnings of approximately 22,000 €, a rather high level in Finland and higher than the average of $16,000 €$ per annum in Tampere. Despite the difference in income, the annual consumption volumes vary significantly less between Tampere and the other cities.

\subsection{Current Carbon Footprints for the Three Case Cities}

The findings of the initial hybrid-LCA assessment are presented next for all case cities, as these results form the basis of the best practice action approach and qualitative analysis. As analyzed further in the following paragraphs, the above presented city characteristics are reflected in the GHG emissions of the average residents.

Figure 1 clearly illustrates how Helsinki has a significantly larger carbon load than the other two cities with 13.6 tons $\mathrm{CO}_{2} \mathrm{e}$ per resident per annum. Tampere and Porvoo on the other hand are very close to each other with 11.4 tons $\mathrm{CO}_{2} \mathrm{e}$ and 11.2 tons $\mathrm{CO}_{2} \mathrm{e}$, respectively. In Porvoo the lower emission factor of the local energy production offsets the impact of the slightly higher consumption than in Tampere, whereas in Helsinki the high consumption volume together with fossil fuel based energy production leads to the result of over $20 \%$ higher carbon load per capita. Meanwhile, the differences in city structures are reflected in both emissions derived from private driving and emissions related to services. Private driving dominates the Ground Transport category in all cities, yet it is only 
1.4 tons $\mathrm{CO}_{2} \mathrm{e}$ in Helsinki while as much as 1.8 tons $\mathrm{CO}_{2} \mathrm{e}$ in Tampere and 2.1 tons $\mathrm{CO}_{2} \mathrm{e}$ in Porvoo. Emissions derived from services, on the other hand, are higher the more dense the city, potentially due to accessibility and availability. Additionally, the proximity of Helsinki to the main airport in the country seems to generate more air traveling.

Figure 1. Current carbon footprint per resident per annum for the three case cities.

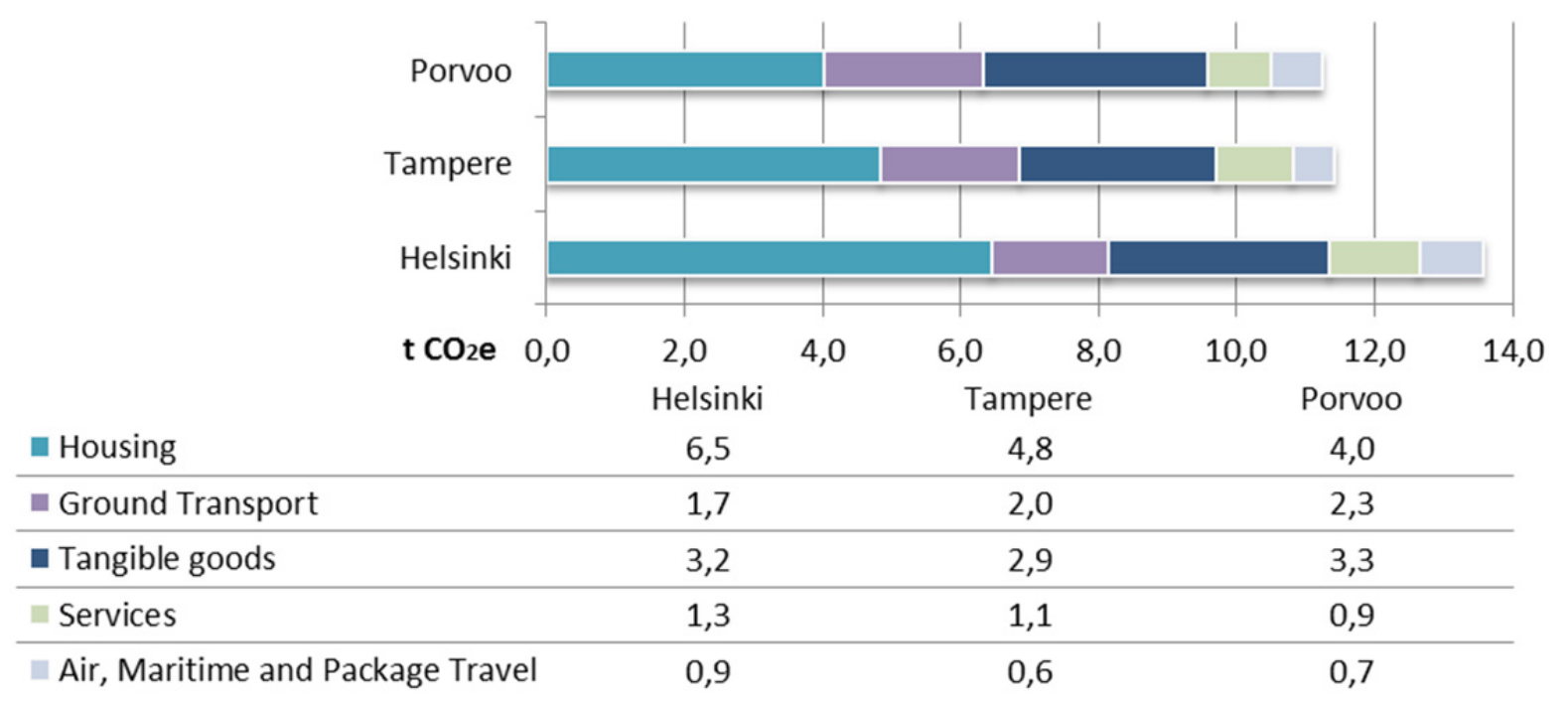

\subsection{Assessed Mitigation Actions}

Following the base case assessment, potential climate change mitigation actions were chosen for the assessment using mainly mitigation strategies stated by the case cities in their policy reports [30-32]. On a general level, all cities are committed to reducing their GHG emissions. Helsinki announces that it strives to reach the goal by infill development, improving energy efficiency and developing rail transport. As more specific goals, the city of Helsinki aims at 7\% energy savings from housing, $20 \%$ renewable fuel use in energy production, and 20\% reduction from transportation [30]. With regard to new residential development, the city is committed to $40 \%$ lower heating energy consumption and $50 \%$ lower electricity consumption than stipulated by the National Building Code of 2010 . The city of Tampere has set an ambitious overall goal of reducing the emissions by $40 \%$ by the year 2030 [32]. The means to achieve the reduction are very similar to those of Helsinki: densifying urban structure, improving alternative transport modes, increasing energy-efficiency of new construction and retrofitting as well as promoting renewable energy use. The share of renewables in the energy production is planned to be at least $20 \%$ by 2020 . Tampere hopes to see a similar reduction on GHG emissions from transportation as Helsinki, namely, 25\%. The energy efficiency of new construction should be increased by $30 \%$ compared to the 2009 requirements. An overall energy conservation goal of $9 \%$ has also been set by both the cities of Tampere and Porvoo. Besides this general goal of $9 \%$, the city of Porvoo has the least outspoken, quantifiable goals for mitigating climate change [31]. The city's strategy does state that it is promoting infill development to reduce the detrimental impacts from private driving, as well as energy production from renewable sources, and low-energy new residential construction.

Based on these outspoken strategies, professional judgment of the authors was employed in choosing the four strategies to be assessed. It was considered particularly essential that the actions would be 
plausible with current technologies and best practice in Finland. Therefore two of the actions reflect prevailing situations in two of the case cities. Helsinki was considered the prime example for density and public transport in the country, whereas the renewables based energy production in Porvoo represents cleaner energy production on a city level. Additionally, the impact of low-energy new construction was assessed since it is stated as an important mitigation strategy by all three case cities. Finally, reducing the energy consumption of the existing building stock is likewise a common goal for the case cities, and is therefore included in the assessment. In conclusion, the four mitigation actions selected for the assessment are as follows: (1) higher density, less VKmT; (2) cleaner energy production; (3) low-energy residential construction, and; (4) improved energy-efficiency of the existing building stock.

\section{Results and Discussion}

This Section presents the different best practice mitigation actions outlined in the previous section. Each subchapter also estimates the potential of the alternative actions for effective carbon mitigation in each respective case city.

\subsection{Higher Density, Less VKmT}

A dense urban structure is often seen as an effective way to reduce carbon emissions, as density tends to limit private driving and the number of passenger-kilometers (pkm), also referred to as vehicle miles or kilometers traveled (VMT or VKmT) [33,34]. In Finland, when it comes to urban density, accessibility to public transport, and VKmT, the capital Helsinki is in a class of its own, and was therefore chosen to be used as a best practice benchmark for the other two cities in the first best practice action of this study. The annual VKmT in Helsinki is by far the lowest in the country, $8100 \mathrm{~km}$ $(22 \mathrm{pkm} / \mathrm{d})$. Tampere, representing a medium-sized city, is close to the national average at 12,600 km (34 pkm/d) whereas Porvoo, as a scarcely populated city with a high rate of residents commuting to the capital city, lies well above the average at 18,400 km (51 pkm/d) [28].

Both Tampere and Porvoo were shifted to the Helsinki level assuming — rather unrealistically — that both density and public transport options would be increased dramatically to reach Helsinki's current daily pkm of only $22 \mathrm{~km}$. The idea is to demonstrate the effect of such change on the carbon footprint of an individual resident within Tampere and Porvoo, living in a dense versus less dense community. For the assessment only the direct petrol combustion phase emissions were taken into account: $1.0 \mathrm{t} \mathrm{CO}_{2} \mathrm{e} / \mathrm{a}$ in Helsinki, $1.5 \mathrm{t}$ in Porvoo and $1.3 \mathrm{t}$ in Tampere. Even though particularly Porvoo, with the most emissions associated with Ground Transport in the base assessment, would achieve a fair emission reduction in this best practice action, it is easy to see that the emission reduction potential is significantly lower than the difference in VKmT between the two cities and Helsinki. The main reason for this un-linear reduction potential lies within the type of driving: Driving in busy traffic in dense urban areas consumes more petrol per kilometer than driving outside cities. To demonstrate this, the above daily VKmT figures were used to calculate the GHGs per kilometer, and the respective city structures seemed to affect the emissions per kilometer significantly. In Helsinki the GHG emissions are $125 \mathrm{~g} / \mathrm{km}$ and in Tampere $102 \mathrm{~g} / \mathrm{km}$, but only $82 \mathrm{~g} / \mathrm{km}$ in Porvoo. This is in accordance with the emissions factors taken from a national study by the Technical Research Centre of Finland [35], which 
estimates the average GHGs to be $82 \mathrm{~g} / \mathrm{km}$ for driving on highways and $182 \mathrm{~g} / \mathrm{km}$ for driving in a city. In Helsinki and Tampere driving is a combination of longer distance highway driving and local city driving, whereas in the more rural Porvoo most driving is of the highway type.

Reducing private driving to the level of the best case in the country, Helsinki, was found to have relatively little impact on the overall carbon footprint. In the base case, the petrol combustion emissions from private driving were 1.5 tons $\mathrm{CO}_{2} \mathrm{e}$ for Porvoo, 1.3 tons $\mathrm{CO}_{2} \mathrm{e}$ for Tampere and 1.0 ton $\mathrm{CO}_{2} \mathrm{e}$ for Helsinki. In other words, despite the significant reductions in VKmT, decreasing the private driving to the level of Helsinki reduces emissions only by 0.5 tons $\mathrm{CO}_{2} \mathrm{e}$ for Porvoo and 0.3 tons $\mathrm{CO}_{2} \mathrm{e}$ for Tampere. Overall, the city of Porvoo would perform best out of the three cities in overall GHG emissions per capita if it would reach the best practice level in private driving. In other words, attempting to decrease the VKmT does seem like a viable mitigation action in the scarcely populated city of Porvoo.

It should be noted however, that in addition to the modest reduction potential, this action is highly uncertain and unrealistic from a number of perspectives. For instance, potential improvements in vehicle, fuel type and combustion technologies are likely to decrease the importance of VKmT in the GHG emissions of individuals in the future. An additional uncertainty is that commuting, which is the most closely linked to urban density [33], comprises only $14 \%$ of all private driving in Tampere, and $17 \%$ in Porvoo and Helsinki. For example private driving related to leisure activities (hobbies, family visits and trips to second homes) represents a larger share (approximately 60\%) of the total VKmT, yet these activities are considered to be more connected to the consumer's socio-economic background than the location of their home [33].

\subsection{Cleaner Energy Production}

The second mitigation action under investigation was a shift towards cleaner energy production. This action has been set as a clear strategy for two of the case cities that currently host a heavily fossil fuel based fuel mix, namely Helsinki and Tampere [30,32].

The effect of cleaner energy was examined using a shift to more renewables used for Helsinki and Tampere, which currently utilize fossil based fuel-mixes. Although currently unfeasible for both Helsinki and Tampere, the share of renewables was elevated to the current best practice within the country, and the related emission factors reduced down to $64 \mathrm{~g} / \mathrm{kWh}$ for electricity and $92 \mathrm{~g} / \mathrm{kWh}$ for heating, as reported by the city of Porvoo [23]. The actions are considered plausible with the use of the current district heating systems, with changes only to the combustion techniques. For the purpose of this study, the increase in the share of renewables was applied for only the direct fuel combustion phase emissions of the energy production. The emissions from the higher order tiers in the production and supply chain were assumed to be the same as in the base case.

When the current best practice in the share of renewable fuels in local energy production is employed to the other two cities, the carbon consumption of an average resident was found to decrease by as much as 2.3 tons $\mathrm{CO}_{2} \mathrm{e}$ in Helsinki and 2.0 tons $\mathrm{CO}_{2} \mathrm{e}$ in Tampere. For comparison, the 20\% share of renewables stated in the climate strategies of both Helsinki and Tampere was also assessed. The $20 \%$ share reduces emissions by 0.6 tons $\mathrm{CO}_{2} \mathrm{e}$ in Helsinki and 0.5 tons $\mathrm{CO}_{2} \mathrm{e}$ in Tampere. The mitigation potential of cleaner energy production is impressive because the impact of improving 
the fuel mix in local energy production is immediate in the whole building stock. Overall, the city of Tampere performs best in this assessment. Most notably, however, Helsinki comes very close to Porvoo, when the current fossil fuel intensive energy production is abandoned.

Besides effective, this mitigation action is considered plausible in the mid-term, as the technology is already in use in one of the case cities. Furthermore, the shift to cleaner energy production will have an even larger effect if all local goods and services are assumed to be produced with local energy, but this evaluation was left outside the scope of this assessment.

\subsection{Low-Energy New Residential Construction}

All three case cities are growing in population, which means that people are moving from existing buildings in other regions into these cities. For example for the city of Tampere this means an estimated 90,000 increase in the number of residents by the year 2030. This increase almost inevitably leads to new residential construction within the cities. In addition, new residential construction is the only way to implement infill development and reach higher urban density, which is considered as guideline for urban development goal in Finland. All the cities state low-energy residential construction as a means to decrease the future GHG emissions in the city. However, construction activities are also a significant source of of GHG emissions, making life-cycle assessments, which consider both the construction phase and the use phase, necessary.

In Finland, strict requirements for the operational energy consumption of new residential buildings have been successfully enforced. The new National Building Code of 2012 stipulates that the theoretical operational energy consumption must be $20 \%$ less than the previous Code of 2010 . Consequently, practically all new residential construction after 2012 can be considered low-energy buildings.

While the implementation of strict operational energy requirements is both important and justified, the motivation behind including this third mitigation action to the study is to draw attention to an important trait of new low-energy construction projects, namely, the significance of construction phase emissions [36]. The authors of this study have referred to the phenomenon as "carbon spike" in previous studies [37]. The carbon spike is comprised of the emissions caused by the construction phase, which are allocated to each future resident of the new residential development.

Although traditionally an object of process-based LCAs, construction phase emissions have been evaluated with IO-based assessments previously [29,37,38]. This assessment uses a previous study [29] to estimate the GHG load of new residential construction at a little over 100 tons $\mathrm{CO}_{2}$ e per resident when all the life cycle emissions of construction, including both the buildings and infrastructure, are included in the assessment. The figure would be very similar for construction projects in each of the case cities as the share of local energy of the emissions is only $7 \%$. The annual operational energy during the use phase of the building is only a fraction of this, especially in low-energy buildings. Thus the carbon payback times become very long, close to 100 years in Helsinki and Tampere. For Porvoo, where the GHGs from the use phase energy consumption are low due to the high share of renewable fuels, the carbon payback time is even longer, and may never be reached.

Figure 2 depicts the very long carbon payback times in the three cities. The assessment assumes a 1\% renewal rate for the residential building stock, in line with statistics published by Statistics Finland on construction activity within the last 10 years in the three cities [39]. In other words, $1 \%$ of the building 
stock is renewed annually with the use phase emissions cut down to the low energy level of $80 \mathrm{kWh} / \mathrm{sqm}$, and the construction phase emissions of approximately 1.6 tons $\mathrm{CO}_{2} \mathrm{e} / \mathrm{sqm}$ [29] are taken into account on the $1 \%$ share. The blue lines in Figure 2 show the cumulative emissions from existing residential building stock with current annual emissions. The green lines mark the effect of increased energy efficiency, without accounting for the construction phase emissions. Comparing these two lines gives the illusion of very positive impacts to GHG emissions. However, the blue lines should be compared to the red lines, depicting both the construction phase emissions using the $1 \%$ annual renewal rate and the lower use phase energy use.

Figure 2. Impacts of construction phase emissions on the green house gases (GHGs) from the residential building stock in the case cities.

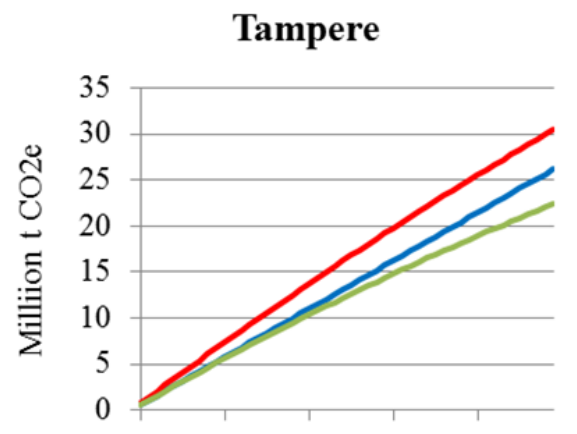

20122022203220422052

Current residential building stock without renewal

Construction and operation with $1 \%$ renewal rate

Operation with $1 \%$ renewal rate

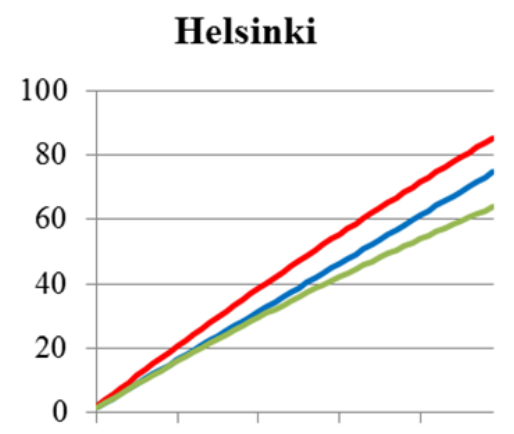

20122022203220422052

Current residential building stock without renewal

Construction and operation with $1 \%$ renewal rate

- Operation with $1 \%$ renewal rate
Porvoo

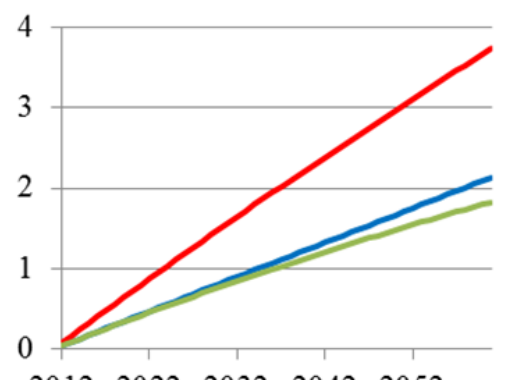

$2012 \quad 2022 \quad 2032 \quad 20422052$

Current residential building stock without renewal

Construction and operation with $1 \%$ renewal rate

Operation with $1 \%$ renewal rate

As Figure 2 shows, the structural differences between the case cities again play an important role. In Porvoo the low-carbon energy fuel mix significantly increases the carbon payback time of the construction phase emissions. Therefore, in case the targets for cleaner energy production outlined in the previous chapter were to be realized in Helsinki and Tampere, the relative importance of the construction phase emissions would further increase in those cities as well.

While there are several limitations to the assessment, particularly that it assumes constant emissions through decades, the overall result is clear: New residential construction cannot be considered as a carbon mitigation action, at least not in the short-term. Two immediate policy implications also arise from the results. First, as new construction in each city will inevitably take place due to migration, more attention should be paid to the construction phase emissions. Second, despite the recent significant development in building energy efficiency requirements, even stricter efficiency requirements are needed in order to shorten the carbon payback times to levels where new construction does not hinder achieving the set mitigation goals of the next decades. 


\subsection{Energy-Efficiency of Existing Buildings}

Improving the energy-efficiency of the existing building stock is generally perceived as an effective and inexpensive means to reduce global GHG emissions, as the built environment is known to account for some $40 \%$ of global GHG emissions [40]. Furthermore, despite the importance of construction phase emissions, the majority of a building's life-cycle emissions are still generated during the operational phase [41].

All three case cities have made a commitment to the governmental energy efficiency program, which aims for a 9\% reduction of energy consumption for the period of 2008-2016 [27]. Following this commitment, the $9 \%$ reduction target is also included in the cities' respective climate change mitigation strategies. The target is based on the average results of energy audits in Finland. According to energy audit statistics, 9\% improvement in building energy efficiency should be achievable by executing only the improvements with $0-1$ year economic payback time [27]. Thus, reaching the $9 \%$ reduction target is considered very feasible.

Assessing the impact of $9 \%$ improvement shows that, all else being equal, the increased building energy efficiency only results in a $0.2-0.3$ ton $\mathrm{CO}_{2} \mathrm{e}$ reduction in the annual carbon footprint of an average city resident of Helsinki and Tampere. In Porvoo the reduction is even smaller, approximately 0.1 tons. It should be noted however, that any reduction in energy consumption would also penetrate other consumption categories, such as services or logistics and slightly increase the mitigation potential, even though this evaluation is outside of the scope of this assessment.

\section{Limitations}

The limitations of the paper can be divided into three categories. First, the hybrid-LCA assessment model includes limitations, both inherent to the method and those arising from the context of use. Second, the case selection and utilized data may lead to biases. Third, the reliability of the results has limitations that need to be defined. Next, these three types of limitations are addressed.

A deficiency present in this model, as it is in all IO-LCAs, is the aggregation of both the input data and the industry sectors. While the input data used for the study comprises approximately 1000 consumption categories, these were merged into only 59 consumption categories to match with the industry sectors of the EIO-LCA model. The employed EIO-LCA model comprises altogether 428 industry sectors, however, making it the most disaggregated model available. It was therefore chosen as the basis of the hybrid model, even though uncertainties are related to using an U.S. industry based EIO-LCA model in a Finnish context. The hybrid assessment reduces the uncertainties, but may also create new possible sources of bias. However, in this study the model was taken as such based on earlier work of the authors. A detailed description of the qualities of the model as well as a profound discussion of the true deficiencies and their gravity can also be found in earlier academic publications of the authors [6].

The study is also limited in scope. The study only addresses three case cities, which makes the sample size rather small. Consequently the risk of bias from abnormal observations is elevated. Nonetheless, the input data from Statistics Finland including over 700 consumers from Helsinki and almost 400 from Tampere significantly reduces this risk. For Porvoo, 65 consumers are included in the 
input data, which was assessed to be sufficient. The selection of the case cities limits the generalizability of the results, however. As was brought up earlier, the selection was based on the cities having different types of structures, but the average residents having similar consumption levels in monetary terms. While this offers a strong basis for an analysis of the impacts of the city type on the GHG emissions of the residents, a larger sample would have both verified the results and shown impacts that are inexistent or impossible to identify from this sample.

Another perspective to evaluating the study is embracing the policy nature of the paper. The assessments did not even strive to be as precise as possible, but rather sought to demonstrate a wider phenomenon. Consequently, the policy implications arising from the study are considered more reliable than the detailed GHG emission levels obtained from the assessments. The analyzed mitigation strategies also present only a few of all the actions that the cities have planned for mitigating climate change. However, based on the professional judgment of the authors, the evidence from earlier publications, and the stated climate strategies, these were selected as the most relevant. This selection, along with the employed best practice approach may also be justified by the policy nature of the paper.

\section{Conclusions}

This study was set out to establish the true global mitigation effect of four typical climate change policy actions in different types of urban communities: (1) dense urban structure with less private driving; (2) the use of energy production based on renewable sources; (3) new low-energy residential construction, and; (4) improving the energy efficiency of existing buildings. Based on the findings, the type of urban community largely determines the mitigation potential of city level action. That said, the most effective climate change mitigation action in the absolute and short-term was found to be to significantly reduce the emission factor of the local energy production. The other three commonly employed mitigation strategies were found to be less effective. Attempting to reduce private driving within a dense urban structure is a rather uncertain and unreliable strategy, with relatively weak effects on the actual carbon emissions. However, in Porvoo, reducing private driving appears much more attractive than in the other two cities due to the already low emission factor of the city's energy production, and loose urban structure with high VKmT per resident. It is also worth noting that dense cities have a number of other positive environmental, social and economic implications that were left outside the scope of this study. With regard to increasing energy efficiency, while the reductions were modest, the target is highly feasible, and in its current scale, even too modest. By accepting a longer economic payback time, more significant energy-efficiency gains would be well within reach. The study also finds that the carbon spike generated by current construction practices is enough to overrule the benefits of the newly constructed low-energy buildings for decades, even a century. Given the accumulation of the GHG emissions into the atmosphere, this phenomenon is even more detrimental from the climate protection perspective.

Some important policy implications for urban carbon management arise from the findings. Minimizing the emissions of the local energy production should be set as a first priority, even if this requires a transition to a decentralized energy system. For the building sector, climate mitigation action should focus on means to lower the emissions derived from the construction phase of new buildings, taking into account both material selection and construction site activities. In the current situation, 
Tampere is the only one of the case cities, which has clearly stated this as a policy goal. More emphasis should also be put on improving the energy-efficiency of the existing building stock more drastically. The policy implications create a need for future research in the fields of, e.g., low-carbon building materials and energy-efficient retrofits.

\section{Conflict of Interest}

The authors declare no conflict of interest.

\section{References}

1. United Nations. City Planning Will Determine Pace of Global Warming, Un-Habitat Chief Tells Second Committee as She Links Urban Poverty with Climate Change; United Nations: New York, NY, USA, 2007. Available online: http://www.un.org/News/Press/docs/2007/ gaef3190.doc.htm (accessed on 7 April 2011).

2. Heinonen, J.; Junnila, S. A carbon consumption comparison of rural and urban lifestyles. Sustainability 2011, 3, 1234-1249.

3. Heinonen, J.; Junnila, S. Implications of urban structure on carbon consumption in metropolitan areas. Environ. Res. Lett. 2011, 6, doi:10.1088/1748-9326/6/1/014018.

4. Heinonen, J.; Kyrö, R.; Junnila, S. Dense downtown living more carbon intense due to higher consumption: A case study of Helsinki. Environ. Res. Lett. 2011, 6, doi:10.1088/17489326/6/3/034034.

5. Heinonen, J. The Impacts of Urban Structure and the Related Consumption Patterns on the Carbon Emissions of an Average Consumer. Doctoral Dissertation, Aalto University School of Engineering, Aalto, Finland, 2012.

6. Sovacool, B.K.; Brown, M.A. Twelve metropolitan carbon footprints: A preliminary comparative global assessment. Energy Policy 2010, 38, 4856-4869.

7. Lenzen, M.; Dey, C.; Foran, B. Energy requirements of Sydney households. Ecol. Econ. 2004, 49, 375-399.

8. Wagner, G. Energy content of world trade. Energy Policy 2010, 38, 7710-7721.

9. Turner, K.; Munday, M.; McGregor, P.; Swales, K. How Responsible is a Region for its Carbon Emissions? An Integrated Input-Output and CGE Analysis; Stirling Economics Discussion Paper, 2011-06; Stirling Management School: University of Stirling, Stirling, UK, 2011. Available online: http:/www.management.stir.ac.uk/research/economics/working-papers (accessed on 10 October 2011).

10. Jones, C.M.; Kammen, D.M. Quantifying carbon footprint reduction opportunities for U.S. households and communities. Environ. Sci. Tech. 2011, 45, 4088-4095.

11. Ramaswami, A.; Hillman, T.; Janson, B.; Reiner, M.; Thomas, G. A demand-centered, hybrid life-cycle methodology for city-scale greenhouse gas inventories. Environ. Sci. Tech. 2008, 42, 6455-6461.

12. Schulz, N.B. The direct material inputs into Singapore's development. J. Ind. Ecol. 2007, 11, 117-131. 
13. Suh, S.; Lenzen, M.; Treloar, G.J.; Hondo, H.; Horvath, A.; Huppes, G.; Jolliet, O.; Klann, U.; Krewitt, W.; Moriguchi, Y. System boundary selection in life-cycle inventories using hybrid approaches. Environ. Sci. Tech. 2004, 38, 657-664.

14. Matthews, H.S.; Hendrickson, C.T.; Weber, C.L. The importance of carbon footprint estimation boundaries. Environ. Sci. Tech. 2008, 42, 5839-5842.

15. Lenzen, M. Errors in conventional and input-output-based life-cycle inventories. J. Ind. Ecol. 2000, 4, 127-148.

16. Treloar, G.J.; Love, P.E.D.; Faniran, O.O.; Iyer-Raniga, U. A hybrid life cycle assessment method for construction. Constr. Manag. Econ. 2000, 18, 5-9.

17. Hendrickson, H.; Horvath, A.; Joshi, S.; Lave, L. Economic input-output models for environmental life-cycle assessment. Environ. Sci. Tech. 1998, 32, 184.

18. Crawford, R.H. Life Cycle Assessment in the Built Environment; Spon Press: London, UK, 2011.

19. Junnila, S. Empirical comparison of process and economic input-output life cycle assessment in service industries. Environ. Sci. Tech. 2006, 40, 7070-7076.

20. Haes, H.A.U.; Heijungs, R.; Suh, S.; Huppes, G. Three strategies to overcome the limitations of life-cycle assessment. J. Ind. Ecol. 2004, 8, 19-32.

21. Input-Output Life Cycle Assessment (EIO-LCA). U.S. 2005 Industry Benchmark Model. Available online: http://www.eiolca.net (accessed on 25 October 2010).

22. Seppälä, J.; Mäenpää, I.; Koskela, S.; Mattila, T.; Nissinen, A.; Katajajuuri, J-M.; Härmä, T.; Korhonen, M-R.; Saarinen, M.; Virtanen Y. Assessment of the Environmental Impacts of Material Flows Caused by the Finnish Economy with the ENVIMAT Model; Finnish Environment: Helsinki, Finland, 2009.

23. Official Statistics of Finland. The Finnish Consumer Survey 2006 (in Finnish); Statistics Finland: Helsinki, Finland, 2006.

24. Energy Statistics 2008 (in Finnish). Available online: http://www.energia.fi (accessed on 20 January 2010).

25. Motiva Ltd Specialist in Energy and Material Efficiency 2011. Available online: www.motiva.fi (accessed on 7 June 2011).

26. The National Building Code of Finland (in Finnish). Available online: http://www.ymparisto.fi/ default.asp?node=12055\&lan=en (accessed on 7 November 2011).

27. Energy Efficiency Agreements and Audits. Available online: http://www.tem.fi/ index.phtml? $1=$ en\&s=2588 (accessed on 15 May 2012).

28. The National Travel Survey 2004-2005 (in Finnish). Available online: http://www.hlt.fi (accessed on 22 March 2012)

29. Säynäjoki, A.; Heinonen, J.; Junnila, S. Carbon footprint assessment of a residential development project. Int. J. Environ. Sci. Dev. 2011, 2, 116-123.

30. Environmental Report for the City of Helsinki (in Finnish). Available online: http://www.hel.fi/wps/wcm/connect/2754e1804a174ae4b2e9fa3d8d1d4668/Ymp\%C3\%A4rist\% C3\%B6raportti+2010.pdf?MOD=AJPERES\&lmod=658620718 (accessed on 16 May 2012).

31. Environmental Program for the City of Porvoo 2010-2020 (in Finnish). Available online: http://www.porvoo.fi/easydata/customers/porvoo2/files/muut_liitetiedostot/hallinto_ja_paatoksen teko/ymparistoohjelma.pdf (accessed on 16 May 2012). 
32. Climate Strategy 2030 for the Tampere Region (in Finnish). Available online: http://www.tampereenseutu.fi/seutuhankkeet/yhdyskunta-suunnittelun_ohjelma/ilmastostrategia_ 2030/ (accessed on 15 April 2011).

33. Ewing, R.; Bartholomew, K.; Walters, J. Growing Cooler: The Evidence on Urban Development and Climate Change; ULI-The Urban Land Institute: Washington, D.C., USA, 2007.

34. Cervero, R.; Kockelman, K. Travel demand and the 3Ds: Density, diversity, and design. Transp. Res. Part D: Transp. Environ. 1997, 2, 199-219.

35. Unit emissions-Passenger traffic-road traffic (in Finnish). Available online: http://lipasto.vtt.fi/ yksikkopaastot/henkiloliikennee/tieliikennee/henkilo_tiee.htm (accessed on 1 March 2010).

36. Dutil, Y.; Rousse, D.; Quesada, G. Sustainable buildings: An ever evolving target. Sustainability 2011, 3, 443-464.

37. Heinonen, J.; Säynäjoki, A.; Junnila, S. A longitudinal study on the carbon emissions of a new residential development. Sustainability 2011, 3, 1170-1189.

38. Sharrard, A.; Matthews, H.; Ries, R. Estimating construction project environmental effects using an input-output-based hybrid life-cycle assessment model. J. Infrastruct. Syst. 2008, 14, 327-336.

39. Building and dwelling production. Available online http://stat.fi/til/ras/index_en.html (accessed on 16 May 2012).

40. UNEP. Buildings and Climate Change-Status, Challenges and Opportunities; UNEP: Paris, France, 2007.

41. Junnila, S.; Horvath, A.; Guggemos, A. Life-cycle assessment of office buildings in Europe and the United States. J. Infrastruct. Syst. 2006, 12, 10-17.

(C) 2012 by the authors; licensee MDPI, Basel, Switzerland. This article is an open access article distributed under the terms and conditions of the Creative Commons Attribution license (http://creativecommons.org/licenses/by/3.0/). 